\title{
Galanin overexpressing transgenic mice
}

\author{
Jacqueline N. Crawley, ${ }^{1}$ Elliott J. Mufson, ${ }^{2}$ John G. Hohmann, ${ }^{3}$ Dawit Teklemichael, ${ }^{3}$ \\ Robert A. Steiner, ${ }^{3}$ Kristina Holmberg, ${ }^{4}$ Zhi-Qing D. Xu, ${ }^{4}$ Karin Hygge Blakeman, ${ }^{5}$ \\ Xiao-Jun Xu, ${ }^{5}$ Zsuzsanna Wiesenfeld-Hallin, ${ }^{5}$ Tamas Bartfai, ${ }^{6,7}$ Tomas Hökfelt ${ }^{4}$
}

\begin{abstract}
${ }^{1}$ Section on Behavioral Genomics, National Institute of Mental Health, Bethesda, MD 20815 USA, ${ }^{2}$ Department of Neurological Sciences and Rush Alzheimer's Disease Center, Rush Presbyterian-St. Luke's Medical Center, Chicago, IL 60612 USA, ${ }^{3}$ Department of Obstetrics and Gynecology \& Department of Physiology and Biophysics, University of Washington School of Medicine, Seattle, WA 98195-7290 USA, ${ }^{4}$ Department of Neuroscience, Karolinska Institutet, S-171 77 Stockholm, Sweden, ${ }^{5}$ Section of Clinical Neurophysiology, Karolinska Institutet, Huddinge University Hospital, S-141 86 Stockholm, Sweden, ${ }^{6}$ Department of Biochemistry and Biophysics, Karolinska Institutet, S-171 77 Stockholm, Sweden, ${ }^{7}$ The Harold L. Dorris Neurological Research Center, Department of Neuropharmacology, The Scripps Research Institute, La Jolla, CA 92037 USA
\end{abstract}

Summary Galanin overexpressing transgenic mice (GAL-tg) were generated on two different promoters. Both lines of GAL-tg displayed high levels of galanin in the hippocampus and reduced sensitivity to seizures, as compared to their respective wildtype littermate controls (WT). Performance deficits on learning and memory tasks, impaired long-term potentiation, reduced hippocampal excitability, lower evoked glutamate release, and reduced numbers of choline acetyltransferase immunoreactive neurons in the horizontal limb of the diagonal band were detected in GAL-tg as compared to WT. Changes in sensitivity to nociceptive stimuli were demonstrated in one line. GAL-tg represent a new model for investigating the biological actions of endogenous galanin, and for testing novel therapeutics based on galanin receptor ligands. (c) 2002 Elsevier Science Ltd. All rights reserved.

\section{INTRODUCTION}

Galanin was discovered almost 20 years ago in the laboratory of Viktor Mutt at Karolinska Institute in Stockholm, Sweden (Tatemoto et al., 1983). The Nterminal sequence of this 29 amino acid neuropeptide (30 amino acids in humans) is highly conserved across species (reviewed in Hökfelt et al., 1991; Bartfai et al., 1992; Crawley, 1995). More recently three galanin receptors have been cloned (reviewed in Iismaa and Shine, 1999; Branchek et al., 2000). Immunocytochemical localization of galanin in the mammalian brain demonstrated a widespread distribution in the rodent peripheral and central nervous systems, with high concentrations of galanin in hypothalamic nuclei, ventral forebrain, amygdala, hippocampus, brainstem and spinal cord (reviewed in Hökfelt et al., 1991, 1998; Merchenthaler et al., 1993;

Received 2 February 2002

Accepted 3 March 2002

Correspondence to: Jacqueline N. Crawley, Ph.D. Chief, Section on Behavioral Genomics, National Institute of Mental Health,

National Institutes of Health, Building 10 Room 4D11, Bethesda, MD, 20892-1375 USA. Tel.: 301486 7855; Fax: 301480 1164;

E-mail: crawleyj@intra.nimh.nih.gov
Pérez et al., 2001; Counts et al., 2001). Coexistence of galanin within the same neuron as a "classical" neurotransmitter was detected, among others, in the rat noradrenergic locus coeruleus, and to a lesser extent in neurons in the cholinergic basal forebrain, serotonergic dorsal raphe, dopaminergic arcuate nucleus, as well as coexistences of galanin with other neuropeptides including cholecystokinin in spinothalamic neurons and vasopressin in hypothalamic neurons (reviewed in Hökfelt et al., 1991; Merchenthaler et al., 1993; Holmes and Crawley, 1995). Coexistences differ across species (Benzing, 1993; Counts et al., 2001).

Exogenously administered galanin has several major physiological and behavioral actions in laboratory animals (reviewed in Hökfelt et al., 1991, 1998; Crawley, 1995; Wrenn and Crawley, 2001). In the spinal cord, galanin has complex actions on pain sensitivity, including attenuation of C-fiber pain transmission and neuropathic pain (reviewed in Xu et al., 2000; Liu et al., 2001). In the rat hypothalamus, galanin induces feeding in satiated rats (reviewed in Crawley, 1999). In the pituitary, galanin induces the release of growth hormone and prolactin (reviewed in Merchenthaler et al., 1993; Wynick et al., 1998), and inhibits the evoked release of corticotropin 
and thyrotropin (Hooi et al., 1990). Given intravenously, galanin reduces norepinephrine levels in plasma, and reduces sympathetic nervous system responses to physiological stressors (degli Uberti et al., 1995; Ceresini et al., 1998). Given intraventricularly, galanin blocks a conditioned place preference to morphine (Zachariou et al., 1999). Galanin appears to mediate behavioral responses to stress responses and anxiety in rodents (Bing et al., 1993; Holmes et al., 1995; Milot and Trudeau, 1997; Möller et al., 1999; Sweerts et al., 2000), and to increase depression-like behaviors (Weiss et al., 1998). Galanin mRNA expression is dramatically elevated after neuronal damage in several systems, suggesting a potential neurotrophic action for galanin (reviewed in Hökfelt et al., 1994, 2000; Holmes et al., 2000; Shi et al., 2001).

Galanin-immunoreactive fibers and terminals appear to hyperinnervate the remaining cholinergic nucleus basalis of Meynert cell bodies in Alzheimer's disease (Chan-Palay, 1988, 1990; Mufson et al., 1993; Bowser et al., 1997). Concentrations of galanin are approximately twice as high in basal forebrain samples from end stage Alzheimer's versus age-matched controls, while cholinergic markers are reduced and other local neuropeptides are unchanged (Beal et al., 1990). Similarly, galanin concentrations are elevated in regions of the cerebral cortex and hippocampus in Alzheimer's versus age-matched controls (Gabriel et al., 1994). The cause and biological significance of galanin overexpression in Alzheimer's disease is under intense investigation.

In rats, galanin appears to play an inhibitory neuromodulatory role. Galanin inhibits the evoked release of acetylcholine and glutamate in rat hippocampal slices and in vivo microdialysate (Fisone et al., 1987; Ögren et al., 1996; Robinson et al., 1996). Galanin attenuates the activation of adenylate cyclase and phosphatidyl inositol hydrolysis in rat hippocampus and cortex (reviewed in Karelson and Langel, 1998; Iismaa and Shine, 1999).

Galanin reduces excitatory activity in CA1 neurons (Dutar et al., 1989) and impairs the development of longterm potentiation in rat hippocampal slices (Sakuri et al., 1996; Mazarati et al., 2000). Galanin administered into the lateral ventricles and ventral hippocampus impairs performance on learning and memory tasks, including $\mathrm{T}$ maze delayed alternation, delayed nonmatching to position, Morris water maze, starburst maze, passive avoidance, and spontaneous alternation (reviewed in Crawley, 1995; McDonald et al., 1998a; Ögren et al., 1998; Wrenn and Crawley, 2001). Deleterious actions of galanin are particularly evident when cholinergic neurotransmission is reduced by treatment with the muscarinic antagonist scopolamine (Robinson et al, 1993) or lesions with a cholinergic immunotoxin (McDonald et al., 1998b).

A good model system is needed to investigate the biological actions of endogenous galanin. Since galanin is normally expressed at very low levels in several systems including the cholinergic basal forebrain neurons and dorsal root ganglia, it seemed reasonable to attempt to create animals that constitutively express high levels of galanin in such systems. For example, it would be interesting to mimic the overexpression of endogenous galanin observed in the basal forebrain in Alzheimer's disease, or in sensory neurons after peripheral nerve damage, to further our understanding of the specific role of galanin in human disease states. In fact, transgenic mice with extra copies of the galanin gene (GAL-tg) have recently been developed, that address this need. Several conditional GAL-tg lines were independently generated. In the line of conditional GAL-tg mice generated by Robert Steiner and coworkers at the University of Washington in Seattle (UW), the galanin gene is linked to a dopamine $\beta$-hydroxylase promoter (Steiner et al., 2001), principally restricting expression to neurons containing norepinephrine and epinephrine. This line was backcrossed for seven generations and bred into a C57BL/6J genetic background. The line of conditional GAL-tg generated by Tomas Hökfelt and coworkers at Karolinska Institute (KI) and Tamas Bartfai and coworkers at Stockholm University in Sweden expressed the galanin gene on a platelet derived growth factor B promoter, yielding wider distribution. This line has been backcrossed for ten generations and bred into a C57BL genetic background. A third galanin overexpressing transgenic line was generated by James Hyde and coworkers at the University of Kentucky, wherein the mouse galanin gene was fused to the rat prolactin promoter, thus providing interesting information on the role of galanin in the anterior pituitary (Cai et al., 1999). The present review focuses on the neuroanatomy of galanin overexpression and its functional consequences in the first two lines of GAL-tg mice, GAL-tg (UW) and GAL-tg (KI), as published at the time of this review (Mazarati et al., 2000; Holmberg et al., 2000; Blakeman et al., 2001; Kehr et al., 2001; Steiner et al., 2001; Kokaia et al., 2001; Holmes et al., 2002).

\section{MUTANT MOUSE PHENOTYPES}

\section{Overexpression levels}

In situ hybridization and quantitation of galanin mRNA in the GAL-tg (UW) revealed five times more galanin mRNA in the locus coeruleus of GAL-tg as compared to WT (Steiner et al., 2001). Ectopic expression of galanin mRNA was detected in the piriform and entorhinal cortex and subiculum, as compared to undetectable levels of galanin mRNA in WT controls (Steiner et al., 2001). In this regard, galanin peptide was not detected in these regions in the normal C57BL/6 mouse brain (Pérez et al., 2001). Radioimmunoassay for total galanin peptide content 
revealed approximately twice as much galanin in the forebrain (Steiner et al., 2001). In a separately bred derivation of GAL- $\operatorname{tg}(\mathrm{UW})$, radioimmunoassay revealed four times as much galanin in the hippocampus, and nine times as much galanin in the cerebral cortex in GAL-tg as compared to WT (unpublished data, Gary Wenk and Lisa Marriott, University of Arizona; JNC and co-workers). Immunocytochemical demonstration of galanin overexpression in the hippocampus of GAL-tg (UW) as compared to WT is illustrated in Figure 1.
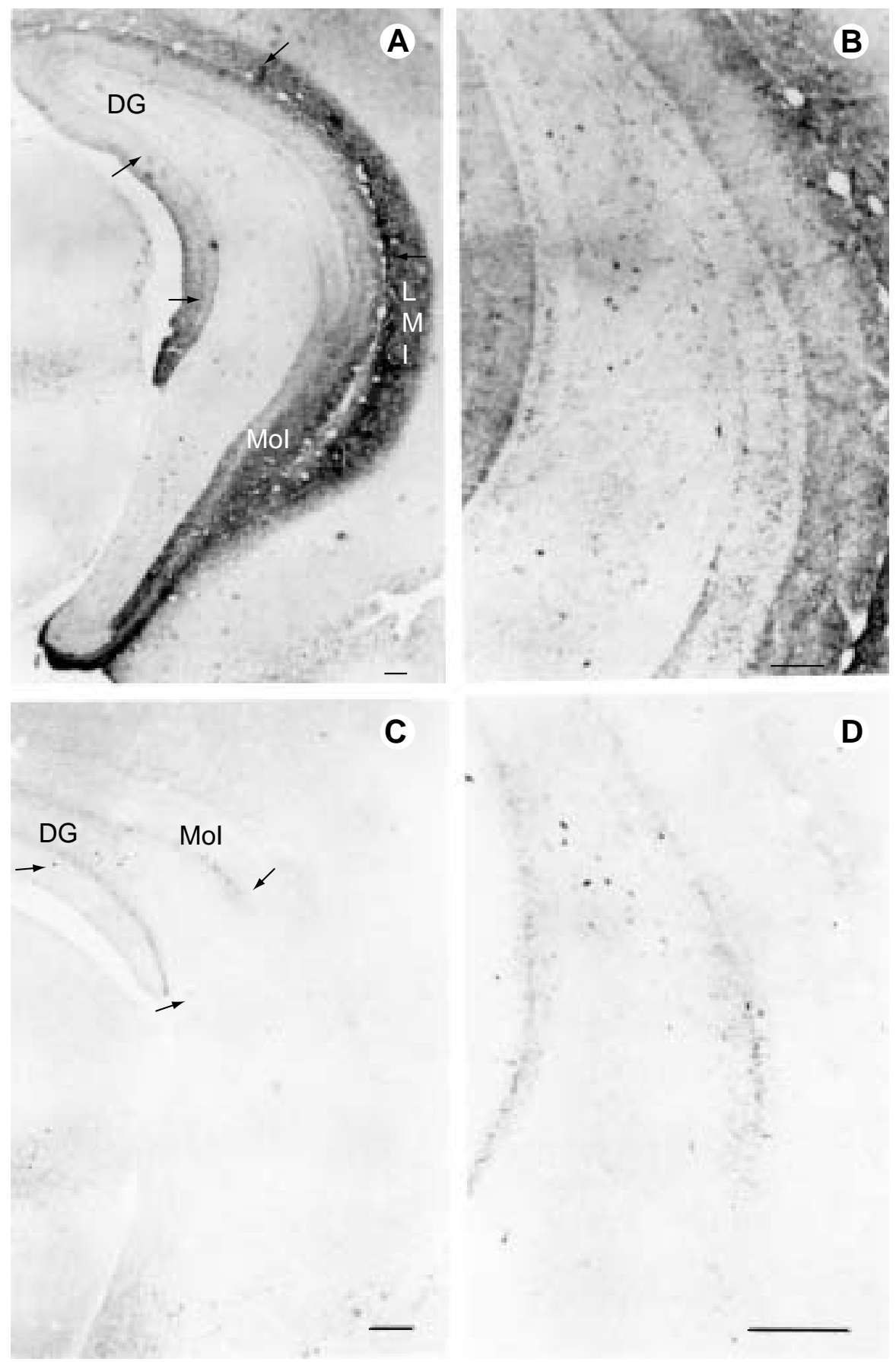

Fig. 1 Coronal sections immunostained for galanin in representative galanin-overexpressing transgenic mice (GAL-tg UW) and wild type control mice. (A) Increased expression of galanin within the inner molecular layer of the hippocampus in GAL-tg. The black arrows indicate the region of the hippocampus shown at a higher magnification in B. Note the scattered galanin immunopositive neurons located in the dentate gyrus. Compare the extensive galanin immunostaining in the hippocampus seen in the GAL-tg to the low amount of staining in this region in a non-transgenic wild type mouse $(C)$. Black arrows indicate the region shown at a high magnification in $\mathrm{D}$. Scale bar $=100 \mu \mathrm{m}$ in A-D. Abbreviations: DG, dentate gyrus; LMI, inner molecular layer of the hippocampus; Mol, outer molecular layer of the hippocampus. 

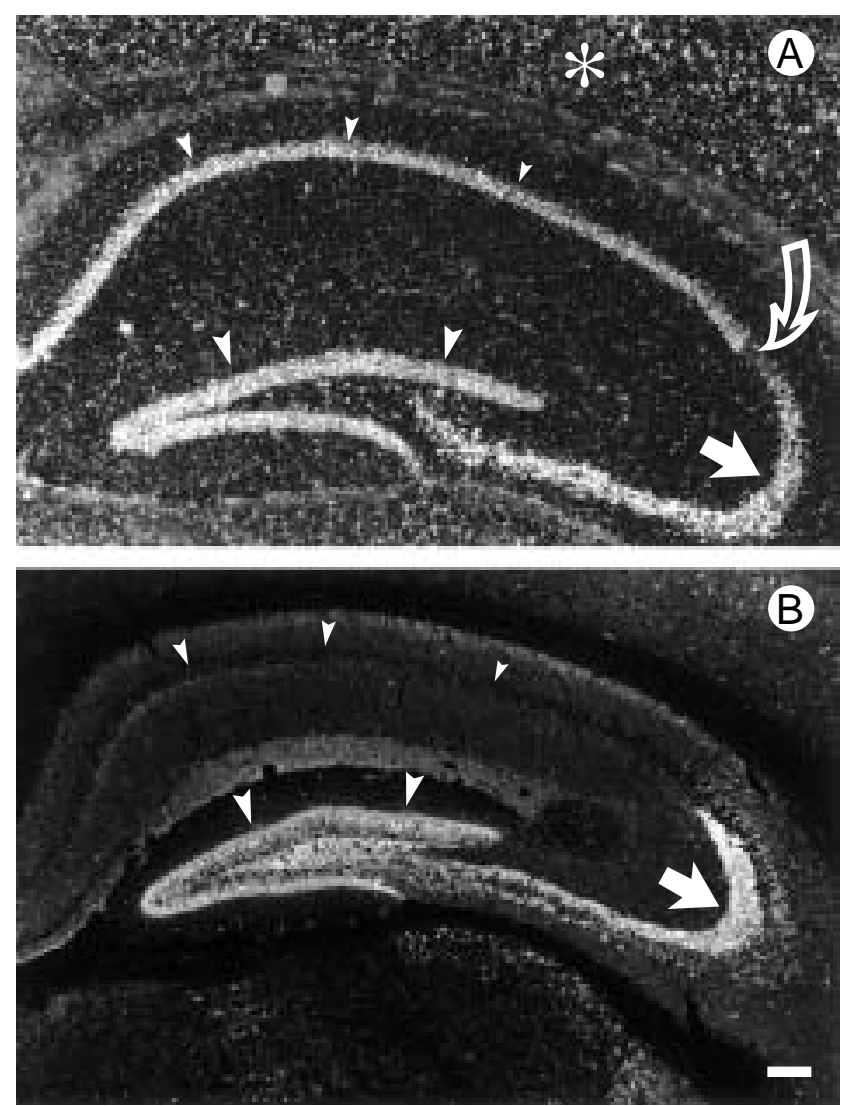

Fig. 2 A, B. Darkfield in situ hybridzation (A) and immunofluorescence (B) micrographs of the dorsal hippocampus of GAL-tg (KI) mice after hybridization with probe complementary to ppgalanin mRNA (A) or after incubation with antiserum to galanin (B). (A) Note strong signal both in the pyramidal cell layer (small arrowheads points to CA1, arrow to CA3), although the signal may be lacking in CA2 (open curved arrow). Also the granular cell layer shows a strong signal (big arrowheads). Note positive cells in cortex $\left({ }^{*}\right)$. (B) Also in the immunohistochemical study the granular cells are labeled (big arrowheads) as well as their terminals, the mossy fibers, in stratum lucidum in CA3 (arrow). Note that in contrast to the in situ hybridization, no galanin-LI can be seen in CA1 or CA3, that is the peptide cannot be detected in the pyramidal cells. Scale bar indicates $50 \mu \mathrm{m}$ for $\mathrm{A}$ and $\mathrm{B}$.

GAL-tg (KI) displayed high levels of galanin mRNA and galanin-like immunoreactivity in, among others, the frontal cortex, parietal cortex, piriform cortex, hippocampal dentate granule and CA1-CA3 cell layers (Figure 2A, $\mathrm{B})$, motoneurons (Figure $3 \mathrm{~A}$ ), sympathetic and dorsal root ganglia, and skin, especially sweat glands (Figure 3C) as compared to WT controls (Figure 3B, D) (Holmberg et al., 2000, 2002; Blakeman et al., 2001; Kokaia et al., 2001). Radioimmunoassay revealed 4-9 fold increases in galanin peptide levels in cortical/hippocampal regions, and HPLC showed that the immunoreactive component eluted in the position of synthetic galanin (Kokaia et al., 2001). A particularly high expression was seen in the granule cellmossy fiber system of the dentate gyrus (Kokaia et al., 2001).

\section{Neurotransmitter release}

Hippocampal slices from GAL-tg and WT (UW) were analyzed for glutamate release (Mazarati et al., 2000). Basal glutamate concentrations were similar in GAL-tg and WT. During $60 \mathrm{mM}$ potassium-induced depolarization, WT displayed the expected increase in glutamate accumulation in the bath, while GAL-tg did not show a significant increase in glutamate accumulation. This result suggests that overexpressed galanin in GAL-tg is released during neuronal stimulation and inhibits the release of glutamate in the mouse hippocampus (Mazarati et al., 2000). Kokaia et al. (2001) indirectly arrived at a similar conclusion with regard to the granule cell-mossy fiber system. Thus, they employed electrophysiological experiments analyzing synaptic transmission at mossy fiber-CA3 cell synapse with so called frequency facilitation, which is a form of short term plasticity where postsynaptic responses are augmented at high frequency stimulation due to increased probability of glutamate release from mossy fibers (Cremer et al., 1998). Such frequency facilitation was low in GAL-tg (KI) mice as compared to WT controls, and the putative galanin antagonist M35 increased this facilitation in GAL-tg but not in WT, suggesting that overexpressed 

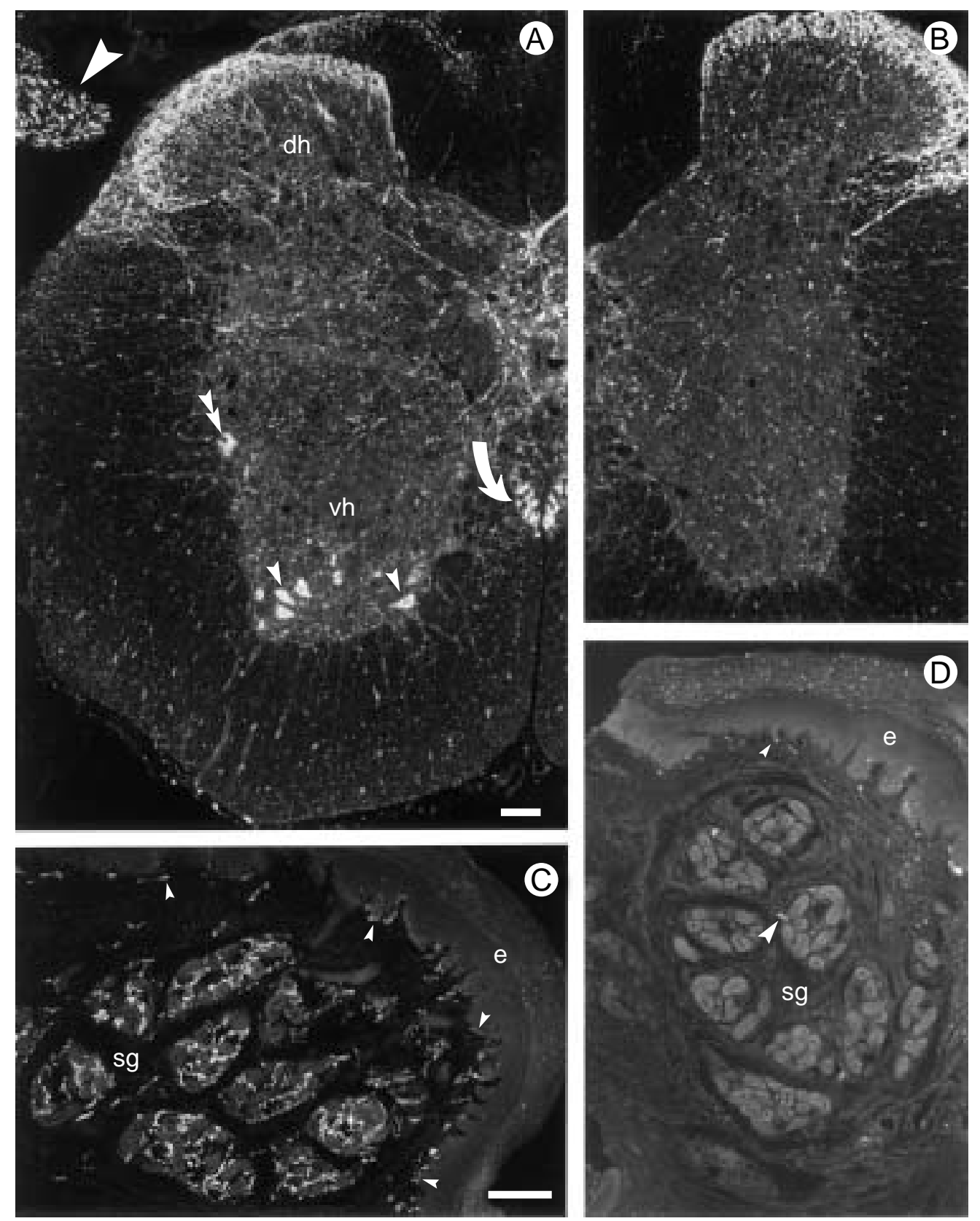

Fig. 3 A-D Immunofluorescence micrographs of the spinal cord (A, B) and skin with sweat gland (sg) (C, D) of GAL-tg (KI) (A, C) or WT (B, D) mice after incubation with antiserum to galanin. (A, B) Both in transgene and WT mouse there is a strong galanin-LI in fibers in the superficial layers of the dorsal horn (dh), which however does not differ distinctly (cf. A with B). Also in the remaining grey matter there is no dramatic difference between the two genotypes. However, note strongly labeled motoneurons (arrowheads) and preganglionic neuron (double arrowhead) in the sympathetic lateral column in the transgene mouse (A), which cannot be seen in the WT (B). Note also strong labeling of dorsal root (large arrowhead in A) and strong galanin-LI close to the midline (curved arrow in A) in the transgene mouse. This cannot be seen in the WT (B). (C, D) Numerous fibers in the sweat gland contain galanin-LI in the GAL-tg (KI) mouse (C), whereas only single fibers can be seen in the WT mouse (big arrowhead in D). The galanin fibers in the sweat gland in the transgene are cholinergic sympathetic fibers. There are also many more galanin-positive fibers close to the epithelium in the transgene (small arrowheads in $\mathrm{C}$ ) as compared to the WT mouse (small arrowhead in D). These fibers are presumably sensory fibers. Fig. D was intentionally overexposed to reveal all possible galanin-positive fibers. Scale bars indicate $50 \mu \mathrm{m}(A=B ; C=D)$.

galanin inhibited glutamate release in this situation (Kokaia et al., 2001). Norepinephrine and serotonin release from 10 month old GAL-tg and WT (KI) was analyzed with in vivo microdialysis in the ventral hippocampus of awake mice (Kehr et al., 2001). Basal levels were similar between genotypes. Intraventricular administration of galanin, 1 nmole, decreased norepinephrine levels to a greater extent in WT than GAL-tg. 
This finding is interpreted as a change in signal transduction mechanisms in GAL-tg (Kehr et al., 2001). Forced swim increased norepinephrine and serotonin levels to a greater extent in the GAL-tg than in the WT. These findings are interpreted as greater sensitivity of GAL-tg to stress, suggesting an anxiogenic action of galanin in these mutant mice (Kehr et al., 2001). Further interpretation of these data will depend on the results of ongoing studies of GAL-tg mice in assays for downregulation and upregulation of galanin receptors, other neurotransmitters and receptors, and alterations in signal transduction mechanisms.

\section{Learning and memory}

GAL-tg (UW) displayed performance deficits on three different types of learning and memory tasks, as summarized in Table 2. GAL-tg and WT were tested at 26 months of age on social transmission of food preference, an olfactory memory task. Mice must remember the odor of a flavored food eaten by a cagemate, to show a preference to eat more of that familiar flavored food than a novel flavored food the next day. WT showed the expected preference for the familiar flavored food, 24 hours after the familiarization interaction. GAL-tg failed to show the expected preference (Steiner et al., 2001). GAL-tg and WT were tested at ages 8 , 16 , and 24 months in the Morris water task. Selective quadrant search was displayed by the WT on the probe trial, as expected. WT mice spent more time in the trained quadrant than in the other three quadrants of the pool, and crossed the former location of the hidden platform more frequently than the analogous locations in the other three quadrants, at all three ages. GAL-tg failed to show a selective quadrant search at all three ages (Steiner et al., 2001). Adult GAL-tg and WT were tested on both standard and trace fear conditioning. Both GAL-tg and WT displayed the expected freezing to the environmental context and to the auditory cue that had previously been paired with footshock in the standard delay version of fear conditioning. However, in the trace version of fear conditioning, when the footshock is separated from the auditory cue by several seconds, the GAL-tg displayed significantly less freezing than the WT (Kinney et al., in press). GAL-tg (UW) were normal on measures of general health, neurological reflexes, sensory abilities including olfaction, vision, hearing, and nociception, and motor abilities including locomotion and swimming to the visible platform (Steiner et al., 2001; Holmes et al., 2002). Therefore, the physical abilities needed to conduct the procedures of the learning and memory tasks were intact. These data support the interpretation that overexpressed galanin impairs cognitive processes across a range of tasks, particularly on the more difficult components of learning and memory tasks. Additional findings that GAL-tg (UW) show impaired long-term potentiation in hippocampal slices (Mazarati et al., 2000), accompanied by reductions in evoked release of glutamate (Mazarati et al., 2000), suggest that a glutamaterigic mechanism in the hippocampus may underlie the cognitive deficits resulting from galanin overexpression (Steiner et al., 2001; Wrenn and Crawley, 2001).

\section{Neuronal survival}

To test whether the cognitive deficits in GAL-tg mice might be associated with perturbations in basal forebrain cholinergic systems, we performed counts of immunoreactive choline acetyltransferase (ChAT)-containing cells in the horizontal limb of the diagonal band (HDB). As shown in Figure 4C GAL-tg (UW) displayed a reduction in choline acetyltransferase immunoreactive cells in the basal forebrain horizontal limb of the diagonal band, as compared to WT (Steiner et al., 2001). No genotype differences were detected in choline acetyltransferase immunoreactive neurons in the medial septum, vertical limb of the diagonal band, or nucleus basalis of Meynert. This finding is discussed in light of one report suggesting that in the horizontal limb of the diagonal band, only the GAL-R1 galanin receptor subtype is expressed, whereas both GAL-R1 and GAL-R2 subtypes are expressed in the vertical limb of the diagonal band (O'Donnell et al., 1999).

To determine whether the apparent loss of identifiable ChAT-containing neurons reflected their death (a frank loss) or simply a reduction in ChAT content to below the limits of detectability by immunocytochemistry, we performed in situ hybridization for ChAT mRNA and measured the number of cells expressing ChAT mRNA, and the average ChAT mRNA content per cell, in the HDB. Figure $4 \mathrm{~B}$ demonstrates a modest reduction in ChAT mRNA per cell in GAL-tg mice as compared to WT mice. However, there was no detectable difference in ChAT mRNA-containing cell counts between the GAL-tg and WT (Figure 4A). These results suggest that galanin overexpression reduces the cholinergic phenotype in the basal forebrain, which could contribute to cognitive deficits in GAL-tg mice. However, actual survival of cholinergic neurons in the HDB appears to be unaffected by the overexpression of galanin in the GAL-tg (UW).

\section{Anxiety}

GAL-tg and WT (UW) displayed similar scores on three tests for anxiety-related behaviors, the elevated plus maze, light $\leftrightarrow$ dark exploration, and open field center time (Holmes et al., 2002). Both WT and GAL-tg showed anxiolytic responses to chlordiazepoxide on the light $\leftrightarrow$ dark exploration test. However, anxiogenic behaviors were induced in WT by yohimbine, an $\alpha 2$ adrenergic 
receptor antagonist, whereas GAL-tg showed no response to yohimbine on light $\leftrightarrow$ dark exploration. These results support the notion that galanin produces an anxiolytic action under conditions of high noradrenergic activation (Holmes et al., 2002).

\section{Seizures}

GAL-tg of both the UW and KI lines displayed reduced susceptibility to evoked seizures (Mazarati et al., 2000; Kokaia et al., 2001), as summarized in Table 1. Kainic

Table 1 Functional studies of mutant mice with galanin gene overexpression (GAL-tg), galanin gene deletion (Galanin -/- ), and GAL-R1 galanin receptor gene deletion (GALR-1R -/-), suggest that galanin controls hippocampal excitability in seizure models via the type 1 galanin receptor subtype

\begin{tabular}{lcc}
\hline Strain & Expression pattern & Major phenotype \\
\hline Galanin $(-/-)^{\mathrm{a}}$ & Galanin deficient & $\begin{array}{c}\text { Sensory neurons } \downarrow \\
\text { Enhanced hippocampal excitability }\end{array}$ \\
GAL-tg-D $\beta H^{\mathrm{b}}(\mathrm{UW})$ & $\begin{array}{c}3-5 \text { fold overexpression } \\
\text { in noradrenergic neurons }\end{array}$ & $\begin{array}{c}\text { Suppressed hippocampal excitability } \\
\text { Cognitive deficit }\end{array}$ \\
GAL-tg-PDGF $\beta^{\mathrm{c}}(\mathrm{KI})$ & $\begin{array}{c}\text { Up to 14 fold over-expression } \\
\text { in several CNS and many } \\
\text { peripheral neurons }\end{array}$ & $\begin{array}{c}\text { Suppressed hippocampal excitability } \\
\text { Changes in pain sensitivity }\end{array}$ \\
GALR 1R $(-/-)^{\mathrm{d}}$ & Galanin R type I deficient & Decreased extravasation \\
& & $\begin{array}{c}\text { Enhanced hippocampal excitability } \\
\text { Spontaneous seizures in some }\end{array}$ \\
\hline
\end{tabular}

${ }^{\mathrm{a}}$ Holmes et al, 2000.

b Steiner et al, 2001.

${ }^{\mathrm{c}}$ Holmberg et al, 2000.

dismaa et al, 2002

Table 2 GAL-tg (UW) displayed deficits on the more difficult components of three learning and memory tasks. Performance was significantly impaired on the Morris probe trial, olfactory memory of a socially transmitted food preference, and trace fear conditioning to an auditory cue. These three tasks represent conceptually different types of memory with divergent sensory and motor demands. Normal scores were seen in GAL-tg (UW) on measures of general health, sensory abilities, and motor functions, and on the less challenging and control components of the cognitive tasks, indicating that GAL-tg mice are physically able to perform all of the procedures required to conduct these tasks. Therefore, the specific learning and memory deficits were not artifacts of physical disabilities. Rather, GAL-tg (UW) demonstrate a highly selective impairment in difficult cognitive tasks

Task

Phenotype

Morris water task (spatial navigation learning and memory)

Probe trial performance

Hidden platform acquisition

Visible platform acquisition

Normal

Social transmission of food preference (olfactory memory)

Preference for familiar scented food

Social interactions

Impaired

Olfactory abilities

Normal

Normal

Cued and contextual fear conditioning (emotional memory)

Trace conditioning freezing to cue

Trace freezing to context

Impaired

Standard freezing to cue

Normal

Standard freezing to context

Normal

Normal

Control measures of general health, sensory abilities, and motor functions

Body weight

Eye blink reflex

Normal

Acoustic startle reflex

Normal

Hot plate reflex

Normal

Righting reflex

Normal

Open field locomotion

Normal

Rotarod motor coordination and balance

Norma

Swim speed

${ }^{a}$ Adapted from Steiner et al., 2001 and Kinney et al. in press. 

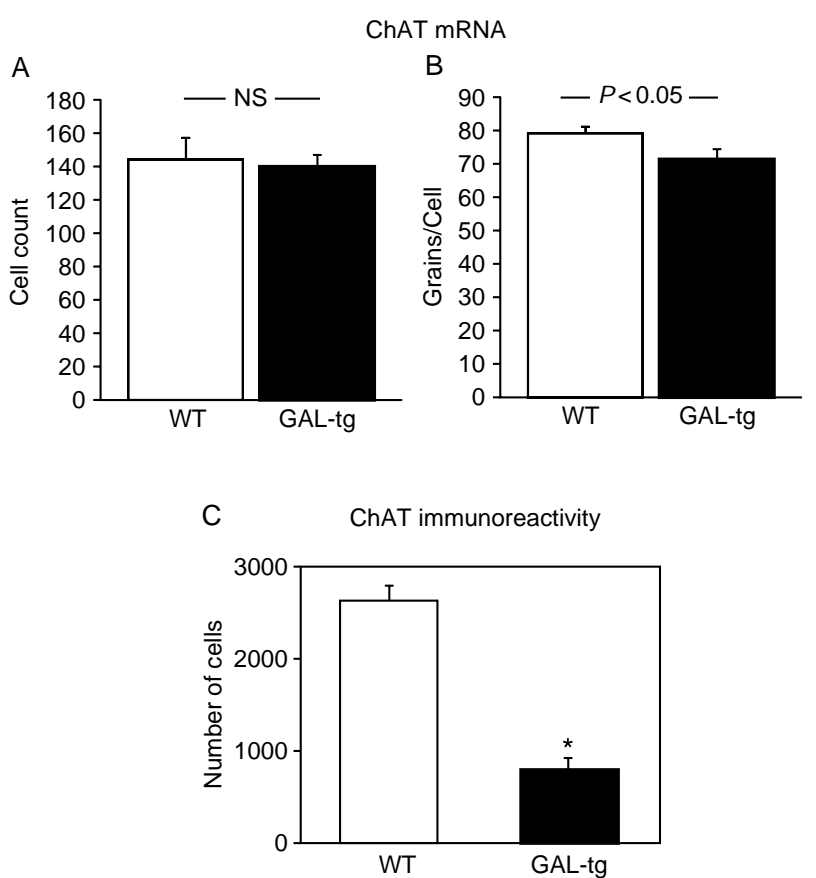

Fig. 4 Levels of choline acetyltransferase (ChAT) mRNA in the horizontal limb of the diagonal band (HDB) in wildtype (WT) and galanin transgenic (GAL-tg) mice (UW). (A) Number of cells expressing ChAT mRNA; (B) Number of silver grains present over each ChAT mRNA-expressing cell; C) Number of cells displaying ChAT immunoreactivity (adapted from Steiner et al., 2001). Data are expressed as mean + standard error of the mean $(\mathrm{N}=6$ per genotype)

acid induced a larger number of stage 5 seizures in WT than in GAL-tg (UW), along with significantly greater numbers of injured neurons in WT than GAL-tg (Mazarati et al., 2000). Pentylenetetrazole induced doserelated seizures that were approximately four-fold more severe in WT than in GAL-tg (UW) (Mazarati et al., 2000). Hippocampal kindling induced seizures in WT with a faster time course than in GAL-tg (KI), and this difference was still present when the animals were re-kindled (Kokaia et al., 2001). Similar results from these three seizure models provides strong corroborative evidence that excess galanin protects against evoked seizures. The mechanism underlying the ability of galanin to reduce the number, severity, and time course of induced seizures is postulated to be the ability of galanin to reduce glutamate release under high levels of neuronal activation (Ben-Ari and Lazdunski, 1989; Mazarati et al., 2000; Kokaia et al., 2001).

\section{Analgesia}

GAL-tg (KI) displayed significantly higher latencies on two measures of pain perception, tail flick and paw withdrawal from radiant heat stimulation, as compared to WT controls (Hygge Blakeman et al., 2001). Responses to mechanical stimulation as measured with Von Frey hairs, and to cold stimulation by acetone drop, were not significantly different between GAL-tg and WT. M35, a peptide analog of galanin with antagonist actions in the spinal cord, reversed the elevated tail flick latency in GALtg. These data support the larger literature describing inhibitory actions of exogenously administered galanin on pain transmission in the spinal cord (Wiesenfeld-Hallin et al., 1992; Xu et al., 2000). In a second series of experiments with GAL-tg (KI), an enhanced pain behavior was observed in the formalin test (Holmberg et al., 2002), underscoring the complexity of the role of galanin in pain control. However, mustard-induced plasma extravasation was attenuated in the transgenic as compared to the WT mouse, supporting previous data on the inhibitory effect of galanin in the peripheral terminals of primary afferents $\mathrm{Xu}$ et al., 1991).

GAL-tg (UW) were not significantly different than WT littermate controls on the hot plate or tail flick tests (Steiner et al., 2001; Holmes et al., 2002). However, recent results by Hygge Blakeman et al. (2001) showed a small, but significant, increase in heat pain threshold in the GAL$\operatorname{tg}$ (UW) mice. The explanation for the discrepancy in findings between the KI and the UW GAL-tg mice and between different laboratories on measures of analgesia remains to be determined, but may be due to differences in the level of golanin over expression in different lines of mice (Holmberg et al., 2002), different methods of nociceptive testing, and the fact that the effect observed by Hygge Blakeman et al. in both GAL-tg (KI) and GAL-tg (UW) is fairly modest. Importantly, however Hygge Blakemen et al. (2002) have recently shown that the development of neuropathic pain-like behaviors was significantly reduced in GAL-tg (UW) compared to WT. This would support the hypothesis that galanin is antinociceptive after nerve injury (Wiesenfeld-Hallin et al., 1992).

\section{ADDITIONAL PARAMETERS}

Measures of general health, home cage behaviors, neurological reflexes, sensory abilities, and motor functions, were normal in GAL-tg (UW) (Steiner et al., 2001, Supplementary Material on-line; Holmes et al., 2002). Breeding was normal on measures of pregnancies, litter size, and pup survival. No genotype differences were detected on gross measures of home cage nesting and group sleeping patterns, appearance of fur and whiskers, righting reflex, eye blink reflex, ear twitch reflex, whisker twitch reflex, body posture or gait. Exploratory locomotion was not significantly different than WT controls on the Digiscan open field measures of horizontal activity and vertical activity. Latency to fall from the rotarod was not significantly different between genotypes. Acoustic startle and prepulse inhibition were not significantly 
different between genotypes. Body weights were not significantly different between GAL-tg and WT controls as measured up to 42 weeks of age. Body temperatures were similar in the two genotypes. The GAL-tg (KI) has so far not been investigated to a similar extent with regards to all of these parameters, but general health appears normal with no differences in body weight between transgenics and WT.

\section{CONCLUSIONS}

The studies conducted to date on two lines of galanin overexpressing transgenic mice indicate that GAL-tg mutant mice are healthy and normal on a variety of physiological and behavioral measures. Specific phenotypic differences in GAL-tg as compared to WT controls were discovered in both lines. GAL-tg displayed lower levels of induced seizures, reduced hippocampal glutamate release, and reduced anxiety-related responses to an anxiogenic drug (Mazarati et al., 2000; Kokaia et al., 2001; Holmes et al., 2002), consistent with previously reported actions of exogenously administered galanin on seizures (Mazarati et al., 1998) and anxiety (Bing et al., 1993). Replication of the seizure resistance in the two independent lines of GAL-tg confirms the reliability of this phenotype, and suggests a potential therapeutic indication for galanin agonists and/or gene transfer in the treatment of epilepsy (Kokaia et al., 2001; Mazarati et al., 2001).

Selective deficits in GAL-tg on learning and memory tasks are consistent with the pharmacological literature showing inhibitory actions of exogenously administered galanin in rats (McDonald et al., 1998a; Wrenn and Crawley, 2001). Galanin overexpressing mice with cognitive deficits represent a new model system to test hypotheses about the role of overexpressed galanin in the memory loss associated with Alzheimer's disease. Lines of galanin overexpressing mice may prove useful for evaluating galanin receptor antagonists for their potential therapeutic efficacy in treating the cognitive symptoms of Alzheimer's disease. Another useful model in this regard is the V717F $\beta$-amyloid precursor protein transgenic mouse, which displays a high level of galanin overexpression in the mossy cells, granule cells, and lamina moleculare-lacunosum layers of the hippocampus (Diez et al., 2000).

Whether Alzheimer's pathological lesions play a role in the induction of the overexpression of galanin is an intriguing question. Human neuropathological studies have shown that neuritic plaques contain galanin (Kowall and Beal, 1989), while neurofibrillary tangles are not immunopositive for galanin (unpublished observations, EJM and coworkers). However, studies using the transgenic mice carrying the mutation $\mathrm{V}-\mathrm{P}$ in position 717 of the human amyloid precursor protein gene (Diez et al., 2000) provide support for the proposition that amyloid plaques may trigger increased galanin expression. In this study, 26 month old transgenic mice that exhibited increased amyloid- containing plaques displayed a striking upregulation of galaninergic fibers in the hippocampus and entorhinal cortex areas that are first affected in Alzheimer's disease (Braak and Braak, 1991). In addition, many of the amyloid plaques contained dystropic, galanin-containing neurites, where occasionally even peptide-positive cell bodies were incorporated in these mutant mice (Diez et al., 2000). Since the hippocampal complex contains extensive amyloid deposition (Brady and Mufson, 1991), it is possible that amyloid may activate galanin overexpression either by a neurotoxic or a neurotrophic effect. In fact, it has been observed that nerve injury in several neural systems causes an up-regulation of galanin synthesis (reviewed in Hökfelt et al., 1994, 2000; Palkovits, 1995). It is, therefore, possible that increases in galaninergic systems seen in both the PDAPP mice and in humans with Alzheimer's disease represent a response to neuronal damage induced by increased $A \beta$ levels. In fact, the increase in galanin in these disease states may represent an attempt aimed at repair. In this regard, we have suggested that the increase seen in galaninergic systems in late stage $\mathrm{AD}$ may be an aborted or end stage plasticity response (Counts et al., 2001). To what extent galanin overexpression in Alzheimer's disease reflects a beneficial action on the neurodegenerative process, and to what extent galanin overexpression causes a worsening of cognitive symptoms, remains to be determined.

It is interesting to compare the cognitive phenotype of the GAL-tg (UW) to the cognitive phenotype of a galanin knockout mouse, described in this volume (Wynick review) and previously (O'Meara et al., 2000). Galanin null mutants were reported to show age-dependent deficits on the Morris water task, significant for genotype at age 10 months but not at age 4 months. This line of galanin knockouts displayed impairments in hippocampal longterm potentiation, and with regard to evoked acetylcholine release in the hippocampus. Thus, the hippocampal and cognitive phenotype in these galanin deficient mice appears to be in the same direction as in the galanin overexpressing mice (GAL-tg UW). However, the cognitive deficits were not age-dependent in the GAL-tg, but rather were detectable as early as age 8 months (Steiner et al., 2001).

Galanin null mutants displayed a loss of choline acetyltransferase immunoreactive (ChAT) cells in the basal forebrain medial septum and vertical limb of the diagonal band (O'Meara et al., 2000). These sets of ChAT-immunoreactive basal forebrain nuclei were normal in the GAL-tg (UW), whereas the GAL-tg (UW) showed lower numbers of ChAT-immunoreactive neurons in the horizontal limb of the diagonal band (Steiner et al., 2001). If replicated, results from the galanin null mutants and GAL-tg suggest 
that there is an optimal concentration of galanin necessary for full cognitive abilities and survival of basal forebrain cholinergic neurons. Either too much galanin or too little galanin appears to be detrimental to cellular components of the cholinergic basal forebrain as well as hippocampal function.

It is interesting to note that the decrease in number of ChAT-immunoreactive neurons in the galanin null mutants is not due to the loss of these neurons but instead is the result of a phenotypic downregulation of specific cholinergic markers. Interestingly, the deletion of the galanin gene results in a reduction in the number of ChAT and trkA immunoreactive neurons in the basal forebrain (O'Meara et al., 2000), but not basal forebrain neurons containing the low affinity p75 neurotrophin receptor $^{(\mathrm{NTR})}$ (Ma et al., 1999). Since virtually all cholinergic basal forebrain neurons contain ChAT as well as the high trkA and low affinity p75 ${ }^{(\mathrm{NTR})}$ receptors (Sobreviela et al., 1994; Gibbs and Pfaff, 1994), these observations suggest that galanin plays a role in the phenotypic regulation of select proteins during the development of cholinergic basal forebrain neurons. Relevant to the hypothesis that galanin may regulate in multiple fashion the expression of specific proteins in neurons, is a new finding that galanin and its three receptors are among a small number of genes uniquely expressed in pluripotent embryonic stem cells as compared to partially differentiated adult stem cells (Anisimov et al., 2002).

The reduction in pain sensitivity in GAL-tg (KI) is consistent with the analgesic actions of exogenously administered galanin in the spinal cord (Wiesenfeld-Hallin et al., 1992; Xu et al., 2000; Wiesenfeld-Hallin and Xu, 2001). Using a GAL-R2 subtype selective agonist, AR-M1896, Liu and coworkers (2001) provided evidence that galanin has nociceptive actions in the spinal cord through a GAL$\mathrm{R} 2$ receptor subtype, in contrast to antiallodynic actions on neuropathic pain at higher doses through a GAL-R1 receptor subtype. This hypothesis can be tested in the future with the use of GAL-R1 deficient mice. GAL-tg mice provide a useful model system to further test galanin receptor subtype-selective compounds for analgesic actions in models of clinical neuropathies.

The GAL-tg model awaits additional key experiments. Correlations between level of overexpression and degree of phenotype may be revealing. Rescue of the several phenotypes by treatment with a galanin receptor antagonist, or a genetic knock-in, or breeding of GAL-tg with galanin null mutants, is a critical test of the assumption that the aberrant phenotypes are caused directly by extra copies of the galanin gene. DNA microarrays of brain regions from GAL-tg and WT controls may discover important genes that are activated or suppressed when galanin is overexpressed throughout development. Downstream genes may represent mechanisms through which galanin overexpression results in phenotypic changes. Compensatory genes may be responsible for masking expected phenotypes in domains such as feeding. Inducible mutations, to increase galanin overexpression during a restricted time period, would allow us to ask more specific questions about the consequences of excess endogenous galanin, e.g. are memory deficits greater when galanin is overexpressed only at older ages. Comparison of phenotypes on the two promoters, and generation of GAL-tg using other relevant promoters, will help to confirm the specificity of each phenotype to galanin overexpression. Galanin overexpressing transgenic mice displaying prominent phenotypes represent a useful research tool to evaluate new nonpeptide, bioavailable, subtype-selective galanin receptor antagonists, to further our understanding of the role of each galanin receptor subtype in the behavioral, physiological, and neurochemical actions of this interesting neuropeptide.

\section{ACKNOWLEDGMENTS}

Research by coauthors of this review article was supported by the National Institute of Mental Health Intramural Resarch Program (JNC), NIH AG10668 (EJM), NICHD SCCPR U54 HD12629 (RAS), NICHD RO1 HD27142 (RAS), NSF/IBN 0110686 (RAS), the Swedish Medical Research Council (2887; TH), Marianne and Marcus Wallenberg's Foundation (TH), and an Unrestricted Bristol-Myers Squibb Neuroscience Grant (TH).

\section{REFERENCES}

Anisimov SV, Tarasov KV, Tweedie D, Stern MD, Wobus AM, Boheler KR (2002) SAGE identification of gene transcripts with profiles unique to pluripotent mouse R1 embryonic stem cells. Genomics 79: 169-176.

Bartfai T, Fisone G, Langel Ü (1992) Galanin and galanin antagonists: molecular and biochemical perspectives. Trends Pharmacol Sci 13: 312-317.

Beal MF, MacGarvey U, Swartz KJ (1990) Galanin immunoreactivity is increased in the nucleus basalis of Meynert in Alzheimer's disease. Ann Neurol 28: 157-161.

Ben-Ari Y, Lazdunski M (1989) Galanin protects hippocampal neurons from the functional effects of anoxia. Eur J Pharmacol 165: 331-332.

Benzing WC, Kordower JH, Mufson EJ (1993) Galanin immunoreactivity within the primate basal forebrain: evolutionary change between monkeys and apes. J Comp Neurol 336: 31-39.

Bing O, Möller C, Engel JA, Söderpalm B, Heilig M (1993) Anxiolyticlike action of centrally administered galanin. Neurosci Lett 164: $17-20$.

Bowser R, Kordower JH, Mufson EJ (1997) A confocal microscopic analysis of galaninergic hyperinnervation of cholinergic basal forebrain neurons in Alzheimer's disease. Brain Pathol 2: 723-730.

Braak H, Braak E (1991) Neuropathological stageing of Alzheimerrelated changes. Acta Neuropathol 82: 239-259. 
Brady DR, Mufson EJ (1991) Alz-50 immunoreactive neuropil differentiates hippocampal complex subfields in Alzheimer's disease. J Comp Neurol 305: 489-507.

Branchek RA, Smith KE, Gerald C, Walker MW (2000) Galanin receptor subtypes. Trends Pharmacol Sci 21: 109-117.

Cai A, Hayes JD, Patel N, Hyde JF (1999) Targeted overexpression of galanin in lactotrophs of transgenic mice induced hyperprolactinemia and pituitary hyperplasia. Endocrinol 140: 4955-4964.

Ceresini G, Sgoifo A, Freddi M, Musso E, Parmigiani S, De Rio G, Va G (1998) Effects of galanin and the galanin receptor antagonist galantide on plasma catecholamine levels during a psychosocial stress stimulus in rats. Neuroendocrinol 67: 67-72.

Chan-Palay V (1988) Galanin hyperinnervates surviving neurons of the human basal nucleus of Meynert in dementias of Alzheimer's and Parkinson's disease: A hypothesis for the role of galanin in accentuating cholinergic dysfunction in dementia. J Comp Neurol 273: 543-557.

Chan-Palay V (1990) Hyperinnervation of surviving neurons of the human basal nucleus of Meynert by galanin in dementias of Alzheimer's and Parkinson's disease. Advan Neurol 51: 253-255.

Counts SE, Perez SE, Kahl U, Bartfai T, Bowser R, Deecher DC, Mash DC, Crawley JN, Mufson EJ (2001) Neurobiology of galanin: Mechanisms and therapeutic potential for Alzheimer's disease. CNS Drug Reviews 7: 445-470.

Crawley JN (1995) Biological actions of galanin. Regul. Peptides 59: $1-16$.

Crawley JN (1999) The role of galanin in feeding behavior. Neuropeptides 33: 369-375.

Cremer H, Chazal G, Carleton A, Goridis C, Vincent JD, Lledo PM (1998) Long-term but not short-term plasticity at mossy fiber synapses is impaired in neural cell adhesion molecule-deficient mice. Proc Natl Acad Sci USA 95: 13242-13247.

degli Uberti EC, Rosaria M, Ambrosio R, Bondanelli M, Trasforini G, Margutti A, Valentini A, Rossi R, Franceschetti P (1995) Human galanin reduces plasma norepinephrine levels in man. J Clin Endocrinol Metab 80: 1894-1898.

Diez M, Koistinaho J, Kahn K, Games D, Hökfelt T (2000) Neuropeptides in hippocampus and cortex in transgenic mice overexpressing V717F $\beta$-amyloid precursor protein - initial observations. Neuroscience 100: 259-286.

Dutar P, Lamour Y, Nicoll RA (1989) Galanin blocks the slow cholinergic EPSP in CA1 pyramidal neurons from ventral hippocampus. Eur J Pharmacol 164: 335-360.

Fisone G, Wu CF, Consolo S, Nordström O, Brynne N, Bartfai T, Melander T, Hökfelt T (1987) Galanin inhibits acetylcholine release in the ventral hippocampus of the rat: histochemical, autoradiographic, in vivo, and in vitro studies. Proc Natl Acad Sci USA 84: 7339-7343.

Gabriel SM, Bierer LM, Davidson M, Purohit DP, Perl DP, Harotunion V (1994) Galanin-like immunoreactivity is increased in the postmorten cerebral cortex from patients with Alzheimer's disease. J Neurochem 62: 1516-1523.

Gibbs RB, Pfaff DW (1994) In situ hybridization detection of trkA mRNA in brain: Distribution, colocalization with p75 NGFR and up-regulation by nerve growth factor. J Comp Neurol 341: 324-339.

Hökfelt T, Bartfai T, Crawley J, Eds (1998) Galanin: Basic Research Discoveries and Therapeutic Implications, Ann NY Acad Sci 863, The New York Academy of Sciences, New York.

Hökfelt T, Bartfai T, Jacobowitz D, Ottoson D, Eds (1991) Galanin: A New Multifunctional Peptide in the Neuro-endocrine System. MacMillan Press, Cambridge, UK.

Hökfelt T, Broberger C, Diez M, Xu ZO, Shi T, Kopp J, Zhang X, Holmberg K, Landry M, Koistinaho J (1999) Galanin and NPY, two peptides with multiple putative roles in the nervous system Horm Metab Res 31: 330-334.

Hökfelt T, Zhang X, Shi T-J, Tong Y-G, Wang HF, Xu ZQ D, Landry M, Broberger C, Diez M, Ju G, Grand G, Villar M (2000) Phenotypic changes in peripheral and central neurons induced by nerve injury: focus on neuropeptides. In: Hayaishi O (Ed.) Challenges for Neuroscience in the 21st Century, Japan Scientific Societies Press, Karger, 63-87.

Hökfelt T, Zhang X, Wiesenfeld-Hallin Z (1994) Messenger plasticity in primary sensory neurons following axotomy and its functional implications. Trends in Neurosci 17: 22-30.

Holmberg K, Kahl U, Karlström H, Lucas G, Hilke S, Theodorsson E, Berge O-G, Lendahl U, Bartfai T, Hökfelt T (2002) Generation and characterization of a galanin over-expressing mouse. Focus on peripheral systems and spinal cord. Submitted.

Holmberg K, Kahl U, Lendahl U, Kokaia Z, Nanobashvili A, Lindvall O, Ekström P, Bartfai T, Hökfelt T (2000) Creation and characterization of a mouse over-expressing galanin. Soc Neurosci Abstr 26: 18.5.

Holmes A, Yang RJ, Crawley JN (2002) Evaluation of an anxietyrelated phenotype in galanin overexpressing transgenic mice. J Mol Neurosci 18: 151-165.

Holmes FE, Mahoney S, King VR, Bacon A, Kerr NCH, Pachnis V, Curtis R, Priestley JV, Wynick D (2000) Targeted disruption of the galanin gene reduces the number of sensory neurons and their regenerative capacity. Proc Natl Acad Sci USA 97: 11563-11568.

Holmes PV, Blanchard DC, Blanchard RJ, Brady LS, Crawley JN (1995) Chronic social stress increases levels of preprogalanin mRNA in the rat locus coeruleus. Pharmacol Biochem Behav 50: 655-660.

Holmes PV, Crawley JN (1995) Coexisting neurotransmitters in noradrenergic neurons. In Psychopharmacology: The Fourth Generation of Progress, F.E. Bloom, and D.J. Kupfer, Eds, Raven Press, New York, pp. 347-353.

Hooi SC, Maiter DM, Martin JB, Koenig JI (1990) Galaninergic mechanisms are involved in the regulation of corticotropin and thyrotropin secretion in the rat. Endocrinology 127 : 2281-2289.

Hygge Blakeman K, Hao J-X, Xu X-J, Hökfelt T, Crawley JN, Iismaa T, Wiesenfeld-Hallin Z (2002) Role of galanin and galanin receptors in nociception and nerve injury: studies using genetically modified mice. Abstract of the IASP $10^{\text {th }}$ World Congress on Pain, 2002.

Hygge Blakeman KH, Holmberg K, Hao JX, Xu XJ, Kahl U, Lendahl U, Bartfai T, Wiesenfeld-Hallin Z, Hökfelt T (2001) Mice overexpressing galanin have elevated heat noiceptive threshold. NeuroReport 12: 423-425.

Iismaa TP, Shine J (1999) Galanin and galanin receptors. In Regulatory Peptides and Cognate Receptors, Richter D, Ed., Springer-Verlag, Heidelberg, Germany, pp. 257-291.

Jacoby AS, Holmes FE, Hort YJ, Shine J, Iismaa TP (2002) Phenotypic analysis of Galr1 knockout mice reveals a role for GALR1 galanin receptor in modulating seizure activity but not nerve regeneration. Lett Pept Sci, in press.

Karelson E, Langel Ü (1998) Galaninergic signaling and adenylate cyclase. Neuropeptides 32: 197-210.

Kehr J, Yoshitake T, Wang FH, Wynick D, Holmberg K, Lendahl U, Bartfai T, Yamaguchi M, Hökfelt T, Ögren SO (2001) Microdialysis in freely moving mice: determination of acetylcholine, serotonin and noradrenaline release in galanin transgenic mice. J Neurosci Methods 109: 71-80.

Kinney JW, Starosta G, Holmes A, Wrenn CC, Yang RJ, Harris AP, Long KC, Crawley JN. Deficits in trace cued fear conditioning in 
galanin-treated rats and galanin-overexpressing transgenic mice. Learning and Memory, in press.

Kokaia M, Holmberg K, Nanobashvilli A, Xu Z-QD, Kokaia Z, Lendahl U, Hilke S, Theodorsson E, Kahl U, Bartfai T, Lindvall O, Hökfelt T (2001) Suppressed kindling epileptogenesis in mice with ectopic overexpression of galanin. Proc Natl Acad Sci USA 98: 14006-14011.

Kowall NW, Beal ME (1989) Galanin-like immunoreactivity is present in human substantia innominata and in senile plaques in Alzheimer's disease. Neurosci Lett 98: 118-123.

Liu HX, Brumovsky P, Schmidt R, Brown W, Payza K, Hodzic L, Pou C, Godbout C, Hökfelt T (2001) Receptor subtype-specific pronociceptive and analgesic actions of galanin in the spinal cord: Selective actions via GalR1 and GalR2 receptors. Proc Natl Acad Sci USA 98: 9960-9964.

Ma SY, Wynick D, Mufson EJ (1999) Differential loss of ChAT and p7 $5^{\mathrm{NTR}}$-containing basal forebrain neurons in mice deficient in galanin. Soc Neurosci Abstr 25.

Mazarati AM, Hohmann JG, Bacon A, Liu H, Sankar R, Steiner RA, Wynick D, Wasterlain CG (2000) Modulation of hippocampal excitability and seizures by galanin. J Neurosci 20: 6276-6281.

Mazarati A, Langel Ü, Bartfai T (2001) Galanin: an endogenous anticonvulsant? Neuroscientist 7: 506-517.

Mazarati AM, Liu H, Soomets U, Sankar R, Shin D, Katsumori H, Langel Ü, Wasterlain CG (1998) Galanin modulation of seizures and seizure modulation of hippocampal galanin in animal models of status epilepticus. J Neurosci 18: 10070-10077.

McDonald MP, Gleason TC, Robinson JK, Crawley JN (1998a) Galanin inhibits performance on rodent memory tasks. Ann NY Acad Sci 863: 305-322.

McDonald MP, Willard LB, Wenk GL, Crawley JN (1998b) Coadministration of a galanin antagonist M40 with a muscarinic $\mathrm{M}_{1}$ agonist improves delayed nonmatching to position choice accuracy in rats with cholinergic lesions. J Neurosci 18: 5078-5085.

Merchenthaler I, Lopez FJ, and Negro-Vilar A (1993) Anatomy and physiology of central galanin-containing pathways. Prog Neurobiol 40: 711-769.

Milot M, Trudeau F (1997) Plasma galanin immunoreactivity in the rat after swimming. Physiol Behav 62: 697-700.

Möller C, Sommer W, Thorsell A, Heilig M (1999) Anxiogenic-like action of galanin after intra-amygdala administration in the rat Neuropsychopharmacol 21: 507-512.

Mufson EJ, Cochran E, Benzing WC, Kordower JH (1993) Galaninergic innervation of the cholinergic vertical limb of the diagonal band (Ch2) and the bed nucleus of the stria terminalis in aging, Alzheimer's disease, and Down's syndrome. Dementia 4: $237-250$

O'Donnell D, Ahmad S, Wahlestedt C, Walker P (1999) Expression of the novel galanin receptor subtype GALR2 in the adult rat CNS: distinct distribution from GALR1. J Comp Neurol 409: 469-481.

Ögren SO, Kehr J, Schött PA (1996) Effects of ventral hippocampal galanin on spatial learning and on in vivo acetylcholine release in the rat. Neuroscience 75: 1127-1140.

Ögren SO, Schött PA, Kehr J, Yoshitake T, Misane I, Mannström P, Sandin J (1998) Modulation of acetylcholine and serotonin transmission by galanin. Ann NY Acad Sci 863: 342-363.

O'Meara G, Coumis U, Ma SY, Kehr J, Mahoney S, Bacon A, Allen SJ, Holmes F, Kahl U, Wang FH, Kearns IR, Ogren SO, Dawbarn D, Mufson EJ, Davies C, Dawson G, Wynick D (2000) Galanin regulates the postnatal survival of a subset of basal forebrain cholinergic neurons. Proc Natl Acad Sci USA 97: 11569-11574.
Palkovits M (1995) Neuropeptide messenger plasticity in the CNS neurons following axotomy. Mol Neurobiol 10: 91-103.

Pérez SE, Wynick D, Steiner RA, Mufson EJ (2001) Distribution of galaninergic immunoreactivity in the brain of the mouse. J Comp Neurol 434: 158-185.

Robinson JK, Crawley JN (1993) Intraseptal galanin potentiates scopolamine impairment of delayed nonmatching to sample. J Neurosci 13: 5119-5125.

Robinson JK, Zocchi A, Pert A, Crawley JN (1996) Galanin microinjected into the medial septum inhibits scopolamineinduced acetylcholine overflow in the rat ventral hippocampus. Brain Res 709: 81-87.

Sakuri E, Maeda T, Kaneko S, Akaike A, Satoh M (1996) Galanin inhibits long-term potentiation at Schaffer collateral-CA1 synapses in guinea-pig hippocampal slices. Neurosci Lett 212 : 21-24.

Shi TS, Tandrup T, Bergman E, Xu ZD, Ulfhake B, Hökfelt T (2001) Effect of peripheral nerve injury on dorsal root ganglion neurons in the C57 BL/6J mouse: marked changes both in cell numbers and neuropeptide expression. Neuroscience 05: 249-263.

Sobreviela T, Clary DO, Reichardt LF, Brandabur MM, Kordower JH, Mufson EJ (1994) TrkA immunoreactive profiles in the central nervous system: Colocalization with neurons containing p75 nerve growth factor receptor, choline acetyltransferase and serotonin. J Comp Neurol 350: 587-611.

Steiner RA, Hohmann JG, Holmes A, Wrenn CC, Cadd G, Juréus A, Clifton DK, Luo M, Gutshall M, Ma SY, Mufson EJ, Crawley JN (2001) Galanin transgenic mice display cognitive and neurochemical deficits characteristic of Alzheimer's disease. Proc Natl Acad Sci USA 98: 4194-4189 and associated online Supplementary Materials.

Sweerts BW, Jarrott B, Lawrence AJ (2000) Acute and chronic restraint stress effects on [125I]-galanin binding in normotensive and hypertensive rat brain. Brain Res 873: 318-329.

Tatemoto K, Rokaeus Å, Jornvall H, McDonald TJ, Mutt V (1983) Galanin - a novel biologically active peptide from porcine intestine. FEBS Lett 164: 124-128.

Weiss JM, Bonsall RW, Demetrikopoulos MK, Emery MS, West CH (1998) Galanin: a significant role in depression? Ann NY Acad Sci 21: 364-382.

Wiesenfeld-Hallin Z, Bartfai T, Hökfelt T (1992) Galanin in sensory neurons in the spinal cord. Front Neuroendocrinol 13: 319-343.

Wiesenfeld-Hallin Z, Xu XJ (2001) Neuropeptides in neuropathic and inflammatory pain with special emphasis on cholecystokinin and galanin. Eur J Pharmacol 19: 49-59.

Wrenn CC, J.N. Crawley JN (2001) Pharmacological evidence supporting a role for galanin in cognition and affect. Prog Neuro-Psychopharmacol \& Biol Psychiat 25: 283-299.

Wynick D, Small CJ, Bacon A, Holmes FE, Norman M, Ormandy CJ, Kilic E, Kerr NC, Ghatei M, Talamantes F, Bloom SR, Pachnis V (1998) Galanin regulates prolactin release and lactotroph proliferation. Proc Natl Acad Sci USA 95: 12671-12677.

Xu XJ, Hao JX, Wiesenfeld-Hallin Z, Håkanson R, Folkers K, Hökfelt T (1991) Spantide II, a novel tachykinin antagonist, and galanin inhibit plasma extravasation induced by antidromic C-fiber stimulation in rat hind paw. Neuroscience 42: 731-737.

Xu XJ, Hökfelt T, Bartfai T, Wiesenfeld-Hallin Z (2000) Galanin and spinal nociceptive mechanisms: recent advances and therapeutic implications. Neuropeptides 34: 137-147.

Zachariou V, Parikh K, Picciotto MR (1999) Centrally administered galanin blocks morphine place preference in the mouse. Brain Res 831: 33-42. 